\title{
The Influence of Active Immunization Against Adrenocorticotropin Hormone on Galactopoiesis in Merino Ewes
}

\author{
Khatereh Bolouri Oskoui ${ }^{1}$; Ahmad Zare Shahneh ${ }^{1,2,}$; Navid Dadashpour Davachi ${ }^{2, *}$; JM. \\ Gooden ${ }^{1}$; Peter C. Wynn ${ }^{1}$ \\ ${ }^{1}$ Dairy Research Unit, Department of Animal Science University of Sydney, Camden, Australia \\ ${ }^{2}$ Department of Animal Science, Faculty of Agriculture and Natural Resource, University of Tehran, Karaj, I.R. Iran \\ ${ }^{*}$ Corresponding authors: Ahmad Zare Shahneh, Navid Dadashpour Davachi, Department of Animal Science, Faculty of Agriculture and Natural Resource, University of Tehran, Karaj, \\ I.R. Iran. Tel:+98-9123446217, E-mail: azareh@ut.ac.ir, dadashpoor@ut.ac.ir
}

Received: October 13, 2013; Revised: December 31, 2013; Accepted: January 5, 2014

\begin{abstract}
Background: Chronic active adrenocorticotropin hormone (ACTH) immunization of ewes (with a previous history of immunization) resulted in elevated titres of antibody against ACTH, which induced a reduction in circulating levels of cortisol.

Objectives: The aim of the present study was to investigate: a) the influence of active immunization against ACTH on milk production of the ewe as assessed by milk intake of the lamb measured with two different methods, b) whether the stimulation of levels of $\beta$-end and $\alpha$-MSH in the circulation can result in a similar increase in the expression of these peptides in the milk of the lactating ewe, thereby producing a milk with high analgesic properties.

Materials and Methods: Ten primiparous Merino ewes (4-5 years old) during their first 5 weeks of lactation were used in the experiment. Milk intake of each lamb can be used to give the ewe's milkyield per unit time, and this can be used for secretion of peptides over time. This was determined by two different techniques: the deuterium oxide method and the weigh-suck-weigh method. $\beta$-end, $\alpha$-MSH and cortisol were measured in blood samples and $\beta$-end, $\alpha$-MSH in milk samples using RIAs (Radio Immune Assay).

Results: Plasma $\beta$-end and $\alpha$-MSH in ACTH-immune animals increased to 3 and 38-fold respectively, although the level of $\alpha$-MSH is most likely exaggerated by the presence of $\alpha$-MSH antibodies in the ACTH immune plasma, as $\alpha$-MSH comprises the N-terminal 13 amino acids of ACTH. Antibodies also were detected in the plasma of lambs of immune ewes after birth, at levels, which were comparable to those measured in the ewes during the period of colostrum production and thereafter decreased to much lower levels by the end of the experiment. Plasma $\beta$-end and $\alpha$-MSH in the lambs of immune ewes were significantly higher than those measured in the lambs of control ewes.

Conclusions:The immunization procedure had no effect on feed intake, live weight gain and milk production of ewes nor was the growth rate or milk intake of the lambs altered. The expression of $\beta$-end and $\alpha$-MSH in milk was also unaffected by the high concentrations of these hormones in the circulation of immune ewes.
\end{abstract}

Keywords: Adrenocorticotropin Hormone; $\alpha$-MSH; $\beta$-endorphin; Immunization

\section{Background}

Both colostrum and milk are complex biological fluids that only contain gross nutrients (such as proteins, carbohydrates, and fats), and micronutrients (such as minerals and vitamins), but also provide an abundant source of biologically active peptides for the new-born and growing lambs. These peptides include EGF, nerve growth factor, insulin, PRL, somatostatin, thyroid releasing hormone, GHRH, luteinizing hormone releasing factor, ACTH, erythropoietin, bombesin like peptides, calcitonin and peptides with opiate activity (1). Many of these are actually circulating hormones, which have been sequestered from the arterial blood supply to the mammary gland via mammary epithelial cells into milk. Alternatively, it is possible that some of these are actually synthesized in the mammary tissue and secreted directly into milk. The function of this maternal source of peptides to the lamb is not well defined, although they are likely to modulate gut maturation, metabolic status and the behavior of the lamb since, many of them have been shown to survive in the acid environment of the GIT of the neonate (2). The opiates are particularly important to the lamb since they induce analgesia, modify behavior and influence feed or milk intake. Furthermore, they may have a direct influence on the maturation of the GIT $(1,3)$.

It is well known that stress-induced release of CRF stimulates the secretion of ACTH and Beta endorphin ( $\beta$-end) from the anterior pituitary with ACTH inducing the secretion of cortisol from the adrenal cortex.

A number of studies have shown that both the imposition of stress and ACTH administration stimulate the secretion of cortisol, both of which decrease milk production and milk protein yield $(4,5)$. 
One physiological mechanism through which cortisol secretion caused by stress may decrease milk production is related to glucose availability. There is a significant correlation between glucose entry rate and mammary uptake of glucose with milk yield in the cow $(6,7)$, where it is required for the synthesis of lactose and protein. The administration of synthetic corticosteroids to cows in vivo results in a decrease in glucose uptake into mammary tissue $(8,9)$ and therefore, presumably less lactose and total milk output.

Thatcher and Tucker (10) have demonstrated that adrenal corticosterone content is correlated with mammary gland mRNA and DNA in the rat. This is in agreement with Baxter (11), Gille et al. (12) and Lofberg et al. (13), who had shown that protein synthesis is reduced by high concentrations of the glucocorticoids through a reduction in DNA synthesis or a decline in the rate of transcription to mRNA.

Active immunization against ACTH results in the production of antibodies against ACTH which decreases the secretion of cortisol and increases the secretion of $\beta$-end and $\alpha-\mathrm{MSH}$ into the circulation (14). This latter result is due to the suppression of negative feedback of either cortisol or ACTH or both on the hypothalamus and pituitary.

\section{Objectives}

The present study investigates: a) the influence of active immunization against ACTH on milk production of the ewe as assessed by milk intake of the lamb measured with two different methods, b) Whether the stimulation of levels of $\beta$-end and Alpha Melanocyt Stimulating Hormone $(\alpha-\mathrm{MSH})$ in the circulation can result in a similar increase in the expression of these peptides in the milk of the lactating ewe, thereby producing milk with high analgesic properties.

\section{Materials and Methods}

Experimental procedures were approved by the University of Sydney Animal Welfare and Ethics Committee.

\subsection{Sheep}

Ten primiparous Merino ewes (4-5 years old) during their first 5 weeks of lactation were used in the experiment. Of the ten ewes, five delivered twin lambs, one of which was withdrawn from the ewe within 24 hours of birth. Lucerne chaff was offered ad libitum to the ewes for the duration of the experiment. Four ewes with a previous history of seven immunizations over a period of two years were used as the ACTH immune group, while six ewes which had received a comparable immunization regime with either Freund's complete or incomplete adjuvant only were used as the control group. The immune ewes were boosted 2 and 18 days after the birth of the lambs, while the control animals received the Freund's incomplete adjuvant alone. The left jugular vein of the sheep was catheterized one day-after parturition and was used to collect blood samples and administer oxytocin and heparin.

\subsection{Measurement Methods}

\subsubsection{Estimation of Milk Intake}

Milk intake of each lamb can be used to give the ewe's milk yield per unit time, and this can be used for secretion of peptides over time. This was determined by two different techniques: the deuterium oxide method and the weigh-suck-weigh method.

\subsubsection{Hormone Measurements}

$\beta$-end, $\alpha$-MSH and cortisol were measured in blood samples and $\beta$-end, $\alpha$-MSH in milk samples using RIAs (Radio Immune Assay). The antibody levels produced in response to active $\mathrm{ACTH}$ immunization were measured by ELISA method.

\subsubsection{Anti $\alpha-M S H$ Antibody Titre}

The ability of the ACTH immune plasma to bind $\alpha-\mathrm{MSH}$ was assessed at lower dilutions of plasma than used in this cross reactivity study.

Samples diluted serially in assay buffer $(100 \mu \mathrm{L})$ were incubated with $10000 \mathrm{cpm}$ of ${ }^{125} \mathrm{I}-\alpha-\mathrm{MSH}$ and $400 \mu \mathrm{L}$ of assay buffer for 12 hours at $4^{\circ} \mathrm{C}$. The final dilutions used were serial dilutions from 1:25 to 1:12800. Normal rabbit serum in $5 \%$ polyethylene glycol $(100 \mu \mathrm{L})$ and donkey antisheep (100 $\mu \mathrm{L} ; 1: 40$ final dilution) were added to tubes and incubated at $4^{\circ} \mathrm{C}$ for a further 12 hours. Tubes were then centrifuged at $2000 \mathrm{~g}$ and the supernatant aspirated. The pellet was counted in a gamma spectrometer, and the antibody titre calculated as that dilution that allowed $50 \%$ of maximum binding.

\section{Results}

\subsection{ACTH Antibody Titres in Immunized Ewes and their Lambs}

\subsubsection{Ewes}

No antibodies were detected in the plasma of control ewes. In contrast, antibodies were detected in the plasma of immune ewes, the levels of which were boosted following each immunization with the ACTH: ovalbumin conjugate (Figure 1). Before the first boost, there were residual circulating antibodies against ACTH from the previous immunization regime, the last boost injection having been administered 32 months before the commencement of this study. However, the titre was doubled one week after the first boost and doubled again one week after the second boost. The assessment of anti- $\alpha-\mathrm{MSH}$ anti- 
body levels showed that there was a titre of 1:3000 in the sample analyzed.

\subsubsection{Lambs}

No antibodies were detected in the plasma of the lambs born from control ewes. In contrast, antibodies were detected in the plasma of the lambs of immune ewes, the levels of which were comparable to those measured in the ewe at the same time and which decreased gradually to a titre of $2030 \pm 174$ by the end of the experiment (Figure 1). The boot immunization of their dams' post-partum did not, however, elevate the circulating antibody levels in the lambs as they did in the dams.

\subsubsection{Feed Intake}

Changes in feed intake in ACTH immune and control ewes during the first 32 days after the birth of the lambs are shown in Figure 2. During the first week post-partum; ewes consumed less than the daily allowance (3-4 kg). However, by week's 2 to 3 post-partum, this ad libitum intake had increased by approximately $50 \%$. There was no significant difference in feed intake between ACTHimmune and control groups, although the feed intake increased significantly $(\mathrm{P}<0.05)$ with time.

\subsection{Body Weight of Ewes and Growth Rate of Lambs}

\subsubsection{Ewes}

The mean body weight of immune and control ewes during the experiment are shown in Figure 3 A. Although the control ewes were heavier compared with the immune ewes during the experiment, this difference was not statistically significant.

\subsubsection{Lambs}

The growth rates of the lambs of immune and control ewes were $188.9 \pm 9.1$ and $212.2 \pm 22.0$ (g.day ${ }^{-1}$ ) respectively. The growth curves of lambs born from immune and control ewes are shown in Figure 3 B. There was no significant difference between the two groups; however, the lambs born from control ewes tended to be heavier at birth and over the total 32-day period.

\subsection{Plasma Hormones}

\subsubsection{Ewes}

\subsubsection{Cortisol}

The mean plasma concentration curves of cortisol of ACTH-immune and controls are shown in Figure $4 \mathrm{~A}$. There was a significant difference between mean values of circulating cortisol of immune and control animals ( $\mathrm{P}$
$<0.05$ ). The concentration of cortisol in the plasma of immune ewes was significantly lower than in control ewes. The immune ewes showed a decrease in circulating levels of cortisol one week after each boost. In contrast, the control ewes showed a rise in cortisol at the same time.

Figure 1. Antibody Titre Response of Merino Ewes and Their Lambs to the Immunization of Ewes Against the ACTH.

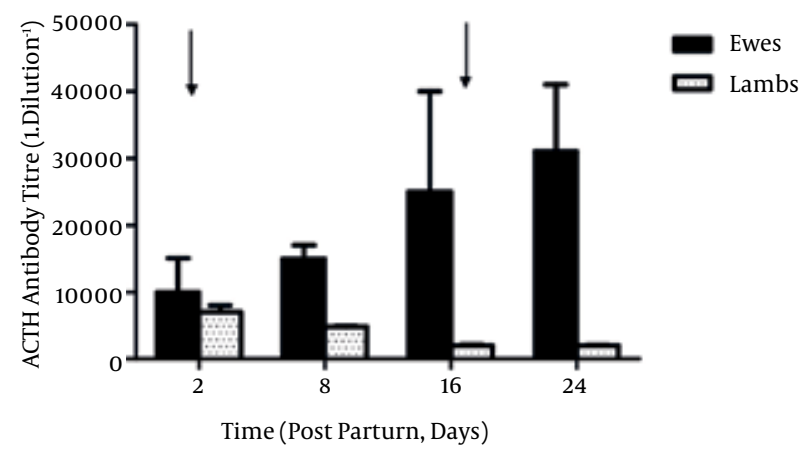

Ovalbumin conjugate (Arrows indicate the time of administration of boost immunizations). (mean \pm SEM).

Figure 2. The Influence of Active Immunization Against ACTH.

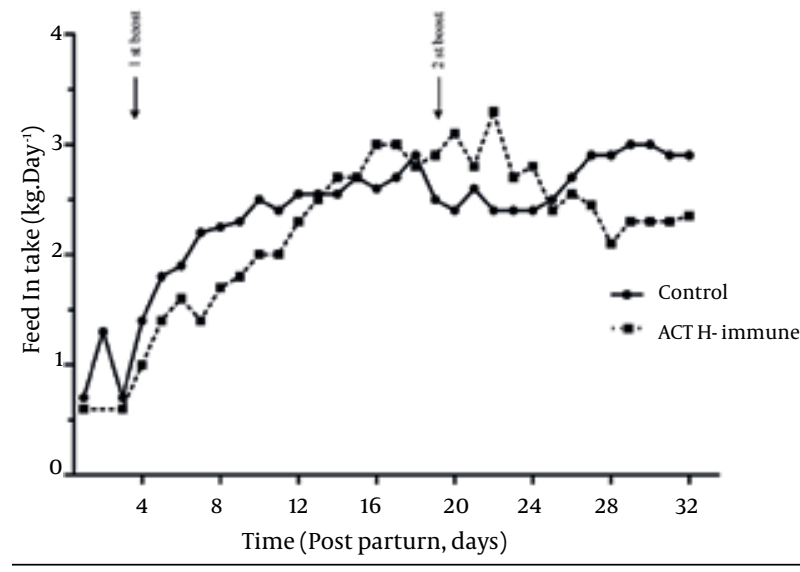

Ovaalbumin or adjuvant alone (control) on feed intake of lactating Merino ewes. (Arrows refer to boost immunization. (mean \pm SEM).

\subsubsection{2. $\alpha-M S H$}

The concentration of circulating $\alpha$-MSH in immune ewes was significantly higher than in control ewes $(\mathrm{P}<$ 0.05 ) (Figure $4 \mathrm{~B}$ ). There was a significant relationship between time and mean concentration of $\alpha-\mathrm{MSH}(\mathrm{P}<0.01)$ in immune animals, with concentrations increasing following the administration of boost immunizations. In contrast, control animals had a low and stable concentration of $\alpha$-MSH during the experiment. 
Figure 3. The Influence of Active Immunization Against ACTH.

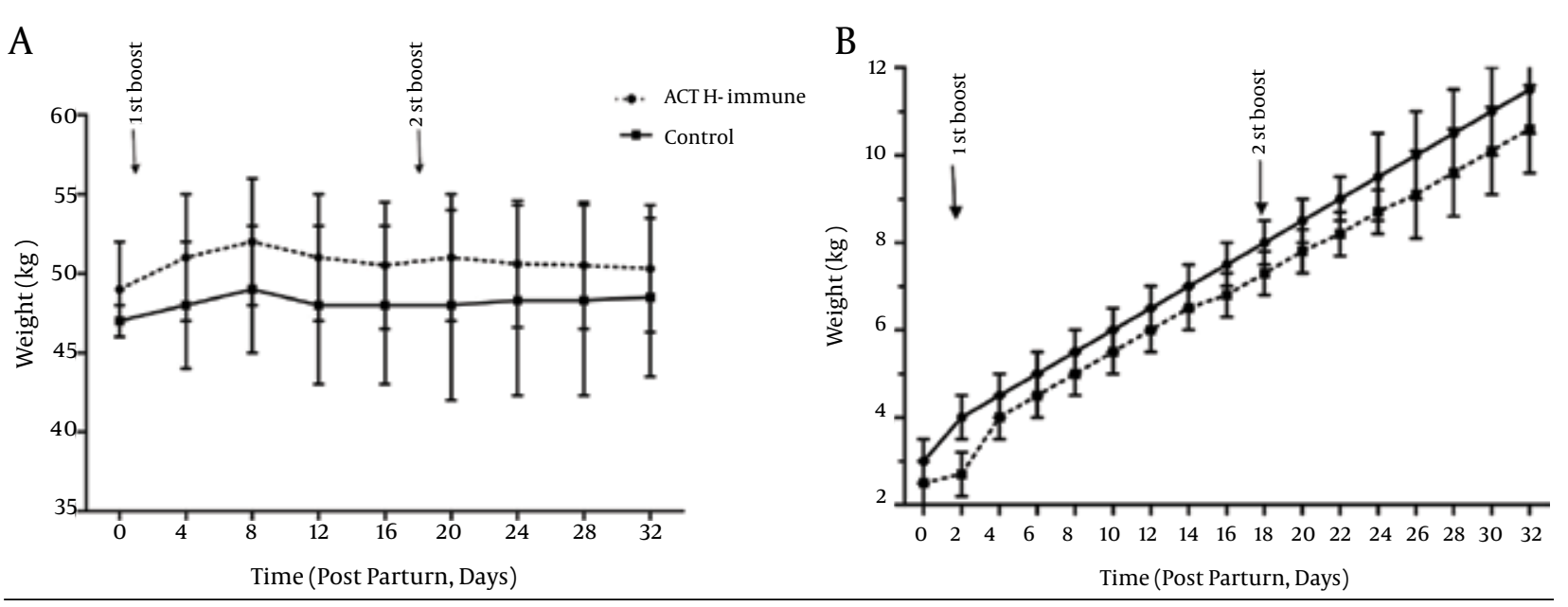

Ovaalbumin or adjuvant alone (control) on feed intake of lactating Merino ewes. (Arrows refer to boost immunization) (mean \pm SEM).

Figure 4. The Influence of Active Immunization Against ACTH.
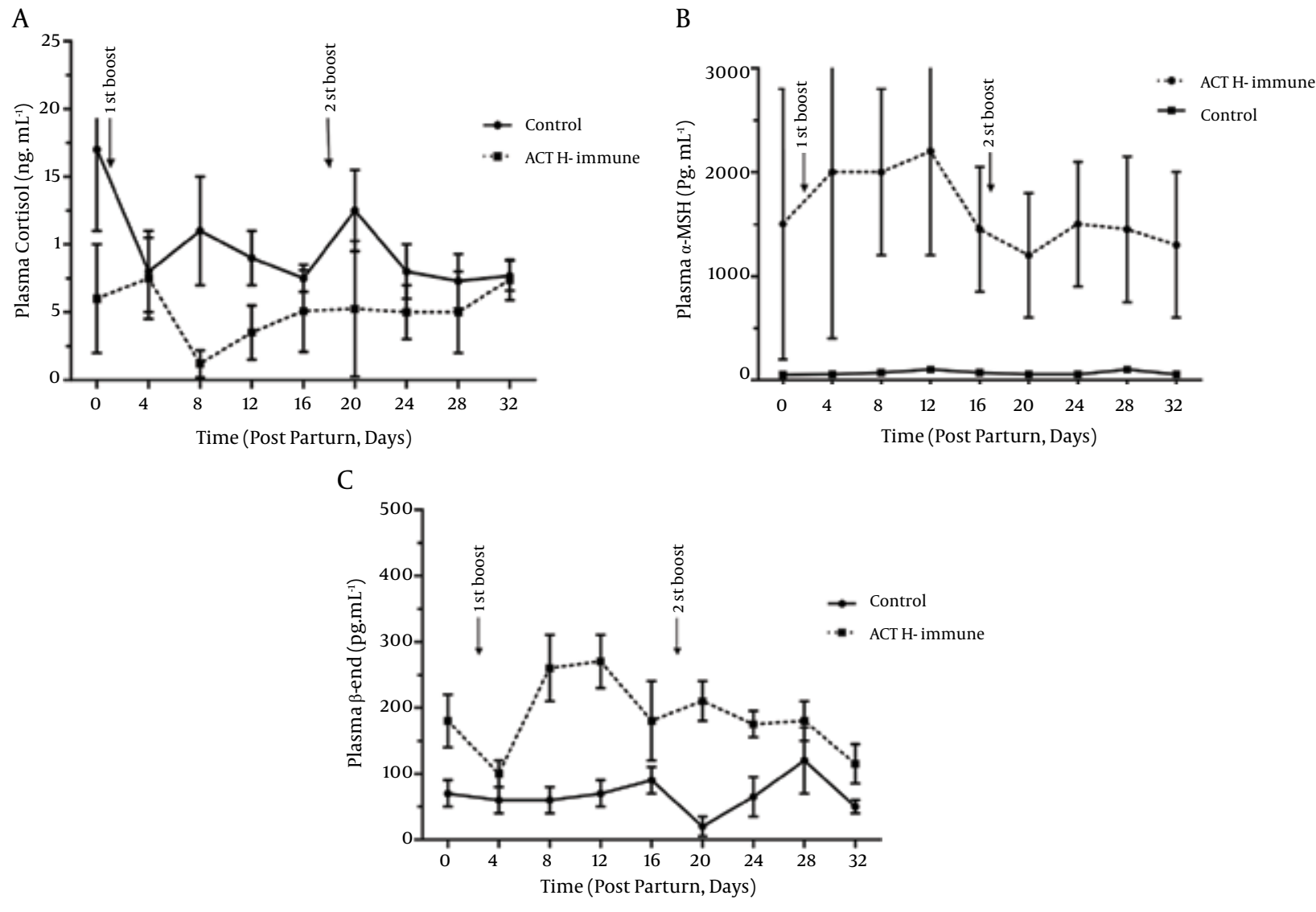

Ovaalbumin or adjuvant alone (control) on plasma cortisol (A), $\alpha$-MSH (B) and $\beta$-end (C) concentrations in lactating Merino ewes. (Arrows refer to boost immunization) (mean \pm SEM). 


\subsubsection{3. $\beta$-end}

The mean circulating concentration curves of $\beta$-the $\beta$ end in ACTH-immune and control animals are shown in Figure $4 \mathrm{C}$. The concentration of circulating $\beta$-end in immune ewes was higher $(\mathrm{P}<0.05)$ than in control ewes.

\subsubsection{Lambs}

\subsubsection{Cortisol}

The mean circulating cortisol levels in lambs born from ACTH-immune and control ewes are shown in Figure 5 A. The lambs born from immune dams had lower concentrations of circulating cortisol at birth and during the last week of the experiment and higher levels during weeks' 2-4 post-partum compared with the lambs born from control dams: this difference was not statistically significant. There was a significant change in plasma cortisol levels with time over the period of the experiment which was reflected as a decrease after birth in both groups.

\subsubsection{2. $\alpha-M S H$}

The mean circulating concentrations of $\alpha$-MSH in lambs born from ACTH-immune and control ewes are shown in Figure 5 B. The lambs from immune dams had significantly higher concentrations of circulating $\alpha-\mathrm{MSH}$ for the period of 32 days post-partum compared with the lambs born from control ewes $(\mathrm{P}<0.01)$. These levels were at their highest immediately after parturition and thereafter decreased throughout the subsequent 32 days, although remaining higher than the levels in control ewes. In contrast, the lambs of control ewes displayed a low and stable concentration of circulating $\alpha$-MSH for the entire 32-day period post-partum.

\subsubsection{3. $\beta$-end}

The mean circulating concentrations of $\beta$-the $\beta$-end in lambs born from ACTH-immune and control ewes are shown in Figure $5 \mathrm{C}$. The lambs born from immune dams had a significantly higher $(\mathrm{P}<0.05)$ concentration of circulating $\beta$-end at birth and during the entire 32-day period of the experiment, although the difference between groups decreased with time.

\subsection{Milk Hormones}

\subsection{1. $\alpha-M S H$}

Changes in mean concentrations of $\alpha-\mathrm{MSH}$ in milk of ACTH-immune and control ewes are shown in Figure 6 A. Although there was a small increase in milk concentration of $\alpha$-MSH in immune animals 10 days after each boost, there was no significant difference in milk concentration of $\alpha$-MSH between the two groups. There was, however, a trend for a decrease in $\alpha$-MSH concentration in milk during the 32day period post-partum in both immune and control ewes.

Figure 5. The Influence of Active Immunization Against ACTH.
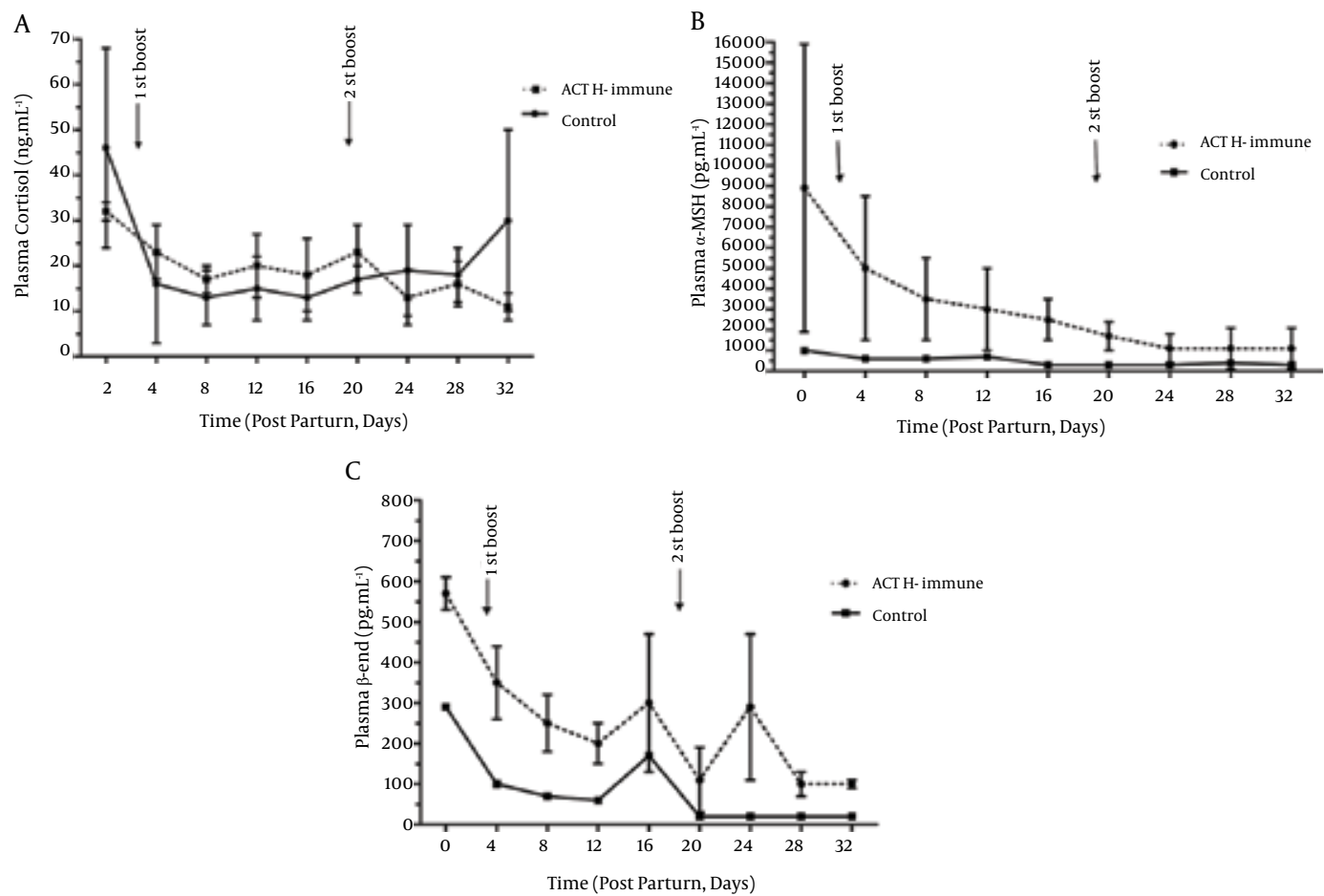

Ovaalbumin or adjuvant alone (control) on plasma cortisol (A), $\alpha$-MSH (B) and $\beta$-end (C) concentrations in lactating Merino ewes. (Arrows refer to boost immunization. (mean \pm SEM). 


\subsection{2. $\beta$-end}

Changes in mean concentration of $\beta$-end in milk of ACTHimmune and control ewes are shown in Figure 6 B. There was no significant difference between the milk concentration of $\beta$-end in immune and control ewes $(P<0.05)$, however, a small increase in milk levels from immune animals occurred 8-10 days after each boost (days 8-12 and 28). These concentrations decreased in both groups over the 5 week period of the experiment (Table 1).

\subsubsection{Milk Intake}

The mean milk intakes of the lambs born from immune and control ewes were $(1226.6 \pm 113.3$ and $1394.1 \pm 162.0$ g.day $\left.{ }^{-1}\right)$ estimated by $\mathrm{D}_{2} \mathrm{O}$ method and $(1235.8 \pm 119.0$ and $1293.4 \pm 159.5$ g.day $\left.^{-1}\right)$ measured by the WSW method respectively (Figure 7). Although the intakes of the lambs from control ewes were higher than those from immune ewes when assessed by either measurement, this difference was not statistically significant.

Table 1. The Mean Concentrations of $\alpha$-MSH and $\beta$-end $\left(\mathrm{pg} \cdot \mathrm{mL}^{-1}\right)$ in Colostrum, Milk and Plasma of Immune and Control Ewes

\begin{tabular}{lllllll}
\hline Peptide & \multicolumn{2}{c}{ Colostrums } & \multicolumn{2}{c}{ Milk } & \multicolumn{2}{c}{ Plasma } \\
\hline & Immune & Control & Immune & Control & Immune & Control \\
$\boldsymbol{\alpha}$-MSH & $82.0 \pm 9.6$ & $84.8 \pm 10.5$ & $60.9 \pm 7.8$ & $60.2 \pm 4.9$ & $1599.2 \pm 795.9$ & $42.1 \pm 19.4$ \\
$\boldsymbol{\beta}$-end & $18.8 \pm 1.1$ & $19.7 \pm 2.2$ & $15.3 \pm 1.6$ & $14.5 \pm 1.4$ & $174.1 \pm 66.9$ & $60.1 \pm 30.5$ \\
\hline
\end{tabular}

Figure 6. The Influence of Active Immunization Against ACTH.
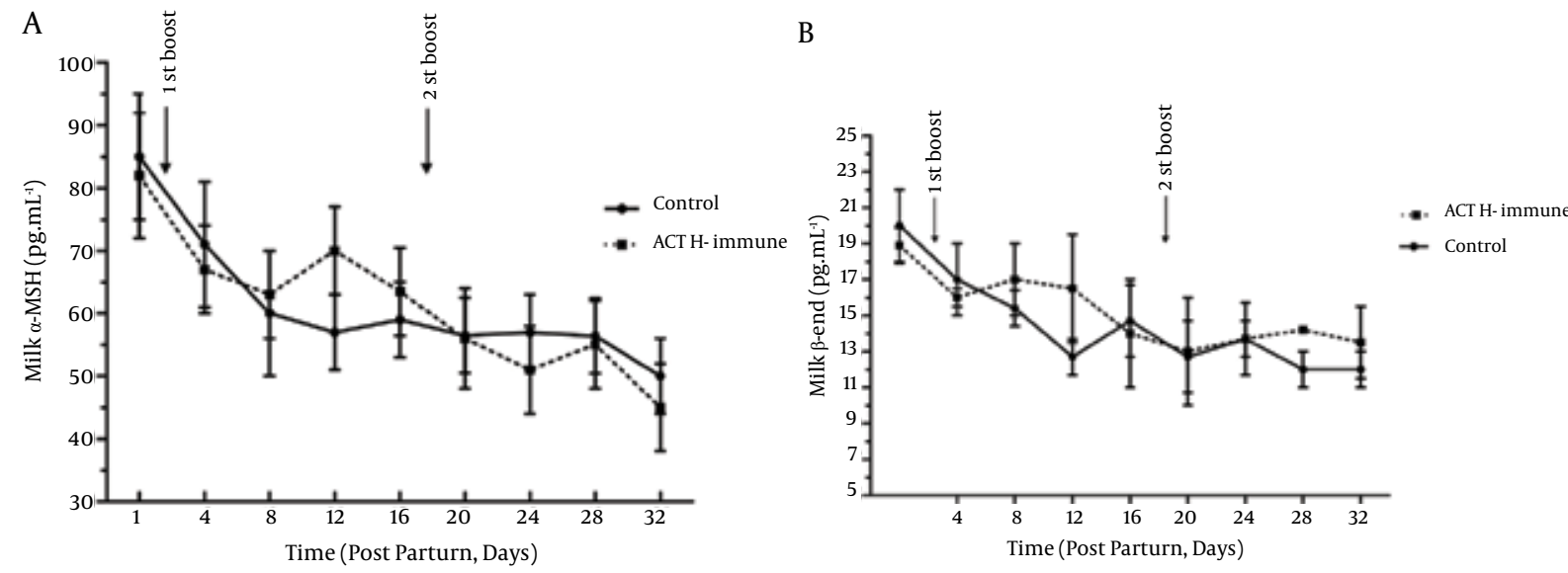

Ovaalbumin or adjuvant alone (control) on milk $\alpha$-MSH (A) and $\beta$-end (B) concentrations in lactating Merino ewes. (Arrows refer to boost immunization) (mean \pm SEM).

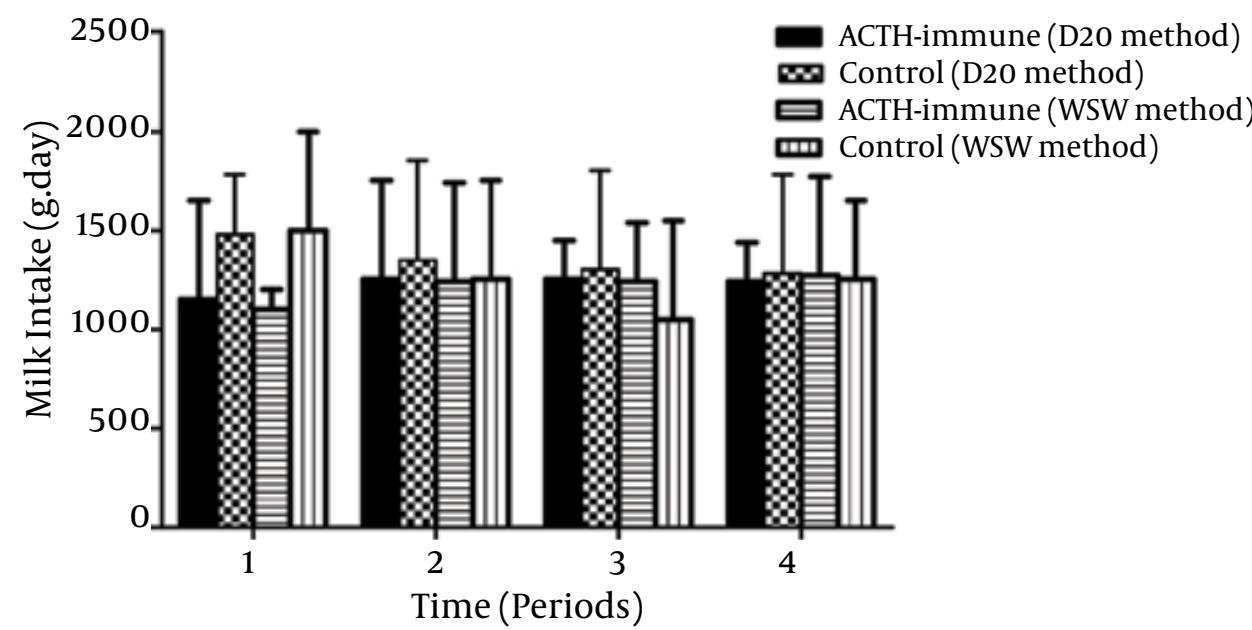

Figure 7. The Mean Milk Intakes of the Lambs of ACTH-Immune and Control Ewes Measured by Weigh-Suck-Weigh (WSW) and D2O Dilution Methods Over Four Periods (mean \pm SEM). 


\section{DISCUSSION}

\subsection{ACTH-Immunisation, Cortisol, $\beta$-end and $\alpha$-MSH}

\subsubsection{Endocrine Status of the Ewes}

The effect of immunization against ACTH was to induce a persistent level of circulatory ACTH antibodies in the ewe (Figure 1), which resulted in a marked reduction in the secretion of cortisol from the adrenal cortex and therefore the circulating levels of cortisol during the total period of the experiment. In view of the low level of specific antibodies directed against ACTH (1-13) ( $\alpha-\mathrm{MSH})$, it would appear that most of the polyclonal response was directed to the C-terminal ACTH (14-39) sequence. Previous experience has shown that the ACTH immunization procedure only suppresses stress induced cortisol levels without affecting basal secretory levels as well (15). Subsequently, the circulating levels of other POMC derived peptides, $\alpha$-MSH and $\beta$-end rose substantially compared to the control ewes $(\mathrm{P}<0.05, \mathrm{P}<0.01$, respectively). This is in agreement with the findings of $(15,16)$, who reported similar rises in circulating levels of these peptides and a decrease in cortisol after active immunization against ACTH. This may be attributed to either the disruption of the negative feedback of corticosteroids or of ACTH itself on the pituitary and hypothalamus $(17,18)$. Presumably the rate of synthesis of either CRF or AVP both from the paraventricular nucleus in the mid- hypothalamus was increased resulting in the release of these peptides from the median eminence. Since we are unable to sample blood from the hypothalamic-pituitary-portal blood system we are unable to substantiate this hypothesis. Alternatively the increase in expression may have resulted from an increase in the sensitivity of corticotrophs to the actions of CRF and AVP through the loss of negative feedback of control and ACTH at that level pituitary. Either way this response would have caused an up-regulation in the transcription and translation of the POMC gene in pituitary corticotrophs $(17,18)$.

The control sheep which were injected with Freund's incomplete only, showed an increase in circulating cortisol one week after each boost $(1,17)$. This may be due to the local inflammatory response by the Freund's adjuvant or to the handling of animals.

\subsubsection{Changes in Milk Hormone Levels}

Milk and colostrums a variety of proteins and steroids that possess biologically activity. Many of these are present in colostrums in higher concentrations than in maternal plasma (1). In studies in which the concentration of hormone/ growth factor has been measured in both colostrum and milk, the highest concentrations occurres in colostrum (19). The measurement of milk concentrations of $\alpha-\mathrm{MSH}$ and $\beta$-end in the present study showed that the level of these peptides was significantly higher in colostrum than in milk in both groups of ewes, which is in accord with the findings of Baumrucker and Blum (19). The $\alpha$-MSH level in colostrum of control sheep was higher $(\mathrm{P}<0.01)$ than in their plasma (on the first dayafter parturition) which is in agreement with the results of Ferrando et al. (20), who also reported higher levels of $\alpha$-MSH and $\beta$-end in human milk than in plasma. However, in contrast, both milk and colostrum had lower concentrations of $\beta$-end when compared with those levels measured in plasma in both treatment groups. This may in part be explained by the lower recovery of $\beta$-end from colostrum and milk than $\alpha-\mathrm{MSH}$.

There was no significant difference between the mean milk level of $\alpha-\mathrm{MSH}$ and $\beta$-end in immune and control sheep (Figure 6 ). This shows that immunization against ACTH has no effect on milk concentrations of these peptides, although systemic circulating levels of both peptides increased markedly. The mechanism for the transfer of such peptides into milk from the circulation is poorly understood. Three possible mechanisms have been considered for the appearance of such bioactive peptides in milk:

1. Passive diffusion from plasma to milk.

2. Active concentration of plasma peptides in the mammary gland acini.

3. Endogenous production of these peptides in mammary epithelial cells during galactopoiesis.

As circulating levels of the peptides, $\alpha$-MSH and $\beta$-end, exceed the levels found in milk, it is possible that they diffuse passively from the bloodstream. However, in the present study, we have shown that this is most likely not the case, since the higher $\alpha$-MSH concentrations found in colostrum were not related to higher levels in circulation.

The possibilities existed that the high circulating levels of $\alpha$-MSH was due to the ACTH-immune plasma containing some antibodies against the $\mathrm{N}$-terminal 13 amino acids of ACTH bound ${ }^{125} \mathrm{I}-\alpha-\mathrm{MSH}$ in the RIA and therefore, artificially increased the measured level. Although a low anti- $\alpha$-MSH antibody titre was found in plasma, the fact that neither $\beta$-end nor $\alpha$-MSH levels varied in the milk between ACTH immune, and control animals suggests that the levels of these 2 peptides was varying in unison. Therefore, it is most likely that $\alpha$-MSH levels were, in fact, increased by the immunization procedure. The extent of the increase, however, awaits HPLC and separation and quantitation by RIA of $\alpha$-MSH extracted from ACTH immune plasma.

In synthesizing colostrum, these peptides are either actively concentrated in the mammary acini or synthesized in the glandular epithelium. The dissociation of plasma and milk concentrations of these peptides is even more graphically illustrated in the ACTH immune ewe, in which there was up to a 40-fold difference in levels of these peptides between plasma and milk. This find- 
ing provides compelling evidence to discount a role for passive diffusion or active concentration of these two biological peptides from the circulation for secretion in milk. As it is likely that these peptides have an important functional role in the neonate, it is not surprising that peptides have an important functional role in the neonate, it is not surprising that peptides do not simply diffuse passively as their role in neonatal development is likely to be concentration dependent. Similarly, these results do not suggest any localized concentration mechanism, unless it is very tightly regulated and in this case suppressed in the ACTH-immune ewes. The validity for such a mechanism could be established by developing a model for suppressing circulating $\alpha$-MSH or $\beta$-end levels, perhaps by inducing active immunity to these peptides. Thus, a protective mechanism for the neonate is in place to prevent any possible deleterious effects of high levels of these peptides being expressed in milk.

\subsubsection{Lambs}

Circulating levels of cortisol in lambs of immune ewes were lower than of those in lambs of control ewes at birth, however, the levels for both groups decreased to similar concentrations within one week of birth. The rise at the time of parturition is consistent with the well- established rise observed in the foetus at birth. This rise is associated to an increase in gluconeogenesis, which ensures the supply of glucose to vital organs during the period between placental separation and the establishment of nutritive sucking in the lamb $(21,22)$. This is confirmed by the demonstration that cortisol appears to induce the activity of most of the gluconeogenic enzymes in the sheep foetus during late gestation (22).

The absence of differences in plasma cortisol levels of lambs in response to ACTH immunization of their dams is difficult to explain, particularly since the lambs of immune ewes show significant increases in circulating levels of $\alpha$-MSH and $\beta$-end compared with the lambs of control ewes. These data would suggest that the negative feedback of ACTH at the glucocorticoids. In concurrent studies $(16,23)$, we have shown that in some ACTH immune animals from which affinity purified anti-ACTH antibodies have been obtained, some antibody populations actually stimulate the release of cortisol from isolated adrenocortical cells in culture rather than prevent ACTH stimulation of cortisol release. In these studies, it has been shown that basal circulating levels of cortisol is unaffected by ACTH immunization, but the response to stress is suppressed. This phenomenon explains the present results and identifies the importance of ACTH in the negative feedback regulation of POMC gene transcription, translation and post-translational processing.

This is also most effectively demonstrated in the neonate, which has been passively immunized against ACTH via the colostrums from the ACTH-immune dam. Thus the passively acquired antibodies have altered the tran- scription and translation of the POMC gene and therefore the circulating levels of $\alpha$-MSH and $\beta$-end presumably by neutralizing circulating ACTH. Again little difference in circulating levels of cortisol was found between the ACTH immune and control lambs.

\subsection{Feed Intake and Live Weight}

Although there is a significant body of evidence to show that opioid peptides stimulate feed intake (24-26), no significant difference was observed between ACTH-immune and control ewes in feed intake and efficiency of conversion to live weight $(P>0.05)$ in spite of low levels of cortisol or high levels of $\beta$-end being present in immune ewes. These observations are consistent with the results of Shahneh (16), who showed that chronic immunization of growing crossbred lambs against ACTH increased plasma $\beta$-end twelve-fold, but did not change feed intake or the efficiency of conversion to live weight. The two groups of ewes also did not lose live weight during the period of five-week post-partum suggesting that feed intake was adjusted to meet the metabolic requirements of lactation.

\subsection{Milk Intake and Growth Rate}

The similar growth rate and milk intake of the lambs of immune and control ewes suggest that immunization against ACTH has not affected milk production from the ewes and growth rate of the lambs. The elevation of circulating $\beta$-end in the passively ACTH immune lamb has not stimulated milk intake. This is not surprising, since no increase in feed intake was observed in the ACTH immune ewes either, even though circulating levels of $\beta$-end were much higher in the ACTH immune ewes.

\subsection{General Discussion}

The answer to the question as whether these important bioactive peptides were transported directly from the circulation to the milk was provided by the study on the influence of active immunization against ACTH on peripheral and milk hormones.

Active immunization against ACTH induced high specific anti-ACTH antibody titres which decreased the secretion of cortisol and increased the secretion of $\beta$-end and $\alpha$-MSH into the circulation of immune ewes. This latter response was presumably due to the suppression of the negative feedback of their cortisol, ACTH or both on the hypothalamus and pituitary. Thus the transcription and translation of the pro-opiomelanocortin gene together with the post-translation modification of this gene have all been up-regulated to account for these high circulating peptide concentrations. The antibodies were also detected in the plasma of the lambs of immune ewes after birth, the levels of which were comparable to those in the ewe at the same time and which decreased subsequently. The boost immunizations of the dams did not alter the 
gradual decline in antibody levels in the lambs with increasing age suggesting that lambs received this antibody via colostrum in the first day's post-partum. Similar results have been reported by Westbrook et al. (25), who demonstrated that passive immunization of lambs with anti-somatostatin antibodies transferred from their antibody immunized dams. These demonstrate how effectively lambs can be immunized against any antigen into the ewe. These demonstrate how effectively lambs can be immunized against any antigen into the ewe. The studies of Westbrook et al. (25) have demonstrated that the efficiency of growth of animals can be improved by using this procedure.

In view of the importance of the endocrine status of the neonate in the first few days post-partum to the process of hormonal imprinting to establish subsequent growth and development patterns $(28,29)$, this procedure may have wider application in boosting other growth characteristics of lambs, or for that matter, other species as well. The lambs born from immune dams had significantly higher concentrations of circulating $\beta$-end and $\alpha$-MSH at birth and for the period of 32 days post-partum compared with the lambs from control ewes, suggesting that the same negative feedback mechanisms were operative in the lambs as in the ewe. Their concentration was much higher (especially $\alpha$-MSH) in the first days after birth to which is in accord with high concentrations of antibodies against ACTH in the circulation of lambs while consuming colostrum. However, caution has to be taken in interpreting the high $\alpha$-MSH levels, as evidence is presented to show that low anti- $\alpha$-MSH antibody titres are present in ACTH-immune plasma. This reflects the fact that the N-terminal 14 amino acids of $\mathrm{ACTH}_{(1-39)}$ comprises $\alpha$-MSH and therefore these antibodies artificially increase circulating levels of $\alpha$-MSH in the RIA because of ability of these antibodies to bind the radiolabelled $\alpha-\mathrm{MSH}$.

There were no significant differences between the mean milk level of these 2 peptides in immune and control sheep which shows that immunization against ACTH has no effect on milk concentration of these peptides, despite the fact that systemic circulating levels of both of those peptides had increased markedly. This result suggests that a protective mechanism for the neonate is in place to prevent any possible harmful effects of high levels of these peptides being expressed in milk. Yet this mechanism must be selective since other peptides appear to be able to pass from the circulation into milk. Gow and Moore (30) showed that milk EGF levels could be elevated by systemic infusion by $50 \%$, while intra-pudendal artery infusion of IGF-I resulted in a similar increase in expression in milk $(7,31)$. There are many other hormones which must also pass from the circulation into milk including pituitary hormones, prolactin and TSH while the hypothalamic releasing factors are well represented by GH realizing hormone, TRH and GnRh $(32,33)$. Of particular interest however are the hormones and growth factors that are expressed in milk at higher concentrations than in plasma. Examples of this phenomenon are GH realizing factor and somatostatin $(34,35)$, both of which appear to be concentrated from the circulation into milk rather than being synthesized in mammary tissue. Thus it is conceivable that the POMC peptides are concentrated from the circulation, although the evidences presented in this study do not agree with this possibility.

As these peptides undoubtedly have important functional roles in the neonate, it is not surprising that peptides do not simply diffuse passively as their role in the neonate is likely to be concentration dependent. In view of this result and the specific localization of these peptides in mammary tissue, it is possible that these two POMC-related peptides, $\beta$-end and $\alpha$-MSH are synthesized in mammary tissue.

Although there is a significant body of evidence to show that opioid peptides stimulate feed intake, in this study no difference was observed between feed intake and efficiency of conversion to live weight in in spite of the changes in endocrine status induced by the immunization procedure. High circulating levels of cortisol have been shown previously to decrease the growth rate of sheep and cattle (36-38), although the ewes in the present study had already attained mature live weight and therefore cannot be classified as growing animals. This is in agreement with the results of Shahneh (37), who reported no change in feed intake or the efficiency of conversion of feed to live weight in spite of ACTH-immune lambs. There was also no significant difference between milk intake and growth rate of the lambs of immune and control ewes suggesting that immunization against ACTH did not affect milk production of the ewes. The lambs and ewes were maintained under 'optimal' conditions, and therefore there was no suggestion that suppressive high levels of cortisol would have been present in these animals, which would be prevented by ACTH immunization.

\section{Acknowledgements}

The author declared there was no acknowledgment.

\section{Author's Contribution}

All authors have participated in the study.

\section{Funding/Support}

The study is funded by Department of Animal Science University of Sydney.

\section{Financial Disclosure}

There is no conflict of interest.

\section{References}

1. Grosvenor CE, Picciano MF, Baumrucker CR. Hormones and growth factors in milk. Endocr Rev. 1993;14(6):710-28. 
2. Wang YY, Zhang Z], Yao W, Morrow A, Peng YM. [Variation of maternal milk adiponectin and its correlation with infant growth] Zhonghua Er Ke Za Zhi. 2011;49(5):338-43.

3. Woo JG, Guerrero ML, Guo F, Martin LJ, Davidson BS, Ortega H, et al. Human milk adiponectin affects infant weight trajectory during the second year of life. J Pediatr Gastroenterol Nutr. 2012;54(4):532-9.

4. Malek Dos Reis CB, Barreiro JR, Mestieri L, Porcionato MA, Dos Santos MV. Effect of somatic cell count and mastitis pathogens on milk composition in Gyr cows. BMC Vet Res. 2013;9:67.

5. Purcell RH, Sun B, Pass LL, Power ML, Moran TH, Tamashiro KL. Maternal stress and high-fat diet effect on maternal behavior, milk composition, and pup ingestive behavior. Physiol Behav. 2011;104(3):474-9.

6. Paterson JY, Linzell JL. Cortisol secretion rate, glucose entry rate and the mammary uptake of cortisol and glucose during pregnancy and lactation in dairy cows. J Endocrin. 1974;62(2):371-83.

7. Nielsen MO, Madsen TG, Hedeboe AM. Regulation of mammary glucose uptake in goats: role of mammary gland supply, insulin, IGF-1 and synthetic capacity. J Dairy Res. 2001;68(3):337-49.

8. Davis SR, Bickerstaffe R. Mammary glucose uptake in the lactating ewe and the use of methionine arterio-venous difference for the calculation of mammary blood flow. Australian J Biologic Sci. 1978;31(2):133-9.

9. Hartmann PE, Kronfeld DS. Mammary Blood Flow and Glucose Uptake in Lactating Cows Given Dexamethasone. J Dairy Sci. 1973;56(7):896-902.

10. Adrenal Function During Prolonged Lactation. In: Thatcher WW, Tucker HA editors. Proceedings of the Society for Experimental Biology and Medicine. Society for Experimental Biology and Medicine (New York, N.Y.). 1970 p. 915-918.

11. Baxter JD. Mechanisms of glucocorticoid inhibition of growth. Kidney Int. 1978;14(4):330-3.

12. Gille J, Reisinger K, Westphal-Varghese B, Kaufmann R. Decreased mRNA stability as a mechanism of glucocorticoid-mediated inhibition of vascular endothelial growth factor gene expression by cultured keratinocytes. J Investigat Dermatol. 2001;117(6):1581-7.

13. Lofberg E, Gutierrez A, Wernerman J, Anderstam B, Mitch WE, Price SR, et al. Effects of high doses of glucocorticoids on free amino acids, ribosomes and protein turnover in human muscle. Eur J Clin Invest. 2002;32(5):345-53.

14. Wynn PC, Behrendt R, Jones MR, Rigby RDG, Bassett JR, Hoskinson RM. Immuno-modulation of hormones controlling growth. Australian J Agri Res. 1994;45(6):1091-1109.

15. Behrendt R, Wynn PC. The influence of ACTH immunisation and genotype POMC peptide secretion in Merino ewes. Endocr Soc Australia.1992;35(143).

16. Shahneh AZ. Manipulation of Ovine Adrenal Function and Animal Productivity. University of Sydney; 1995.

17. Keller-Wood ME, Dallman MF. Corticosteroid inhibition of ACTH secretion. Endocr Rev. 1984;5(1):1-24.

18. Hill MN, Tasker JG. Endocannabinoid signaling, glucocorticoidmediated negative feedback, and regulation of the hypothalamic-pituitary-adrenal axis. Neuroscience. 2012;204:5-16.
19. Grosvenor CE, Picciano MF, Baumrucker CR. Hormones and growth factors in milk. Endocr Rev. 1993;14(6):710-28.

20. Mastorakos G, Ilias I, editors. Maternal and fetal hypothalamicpituitary-adrenal axes during pregnancy and postpartum. Annals NY Academy of Sciences; 2003 Nov.

21. Barnes RJ, Comline RS, Silver M. The effects of bilateral adrenalectomy or hypophysectomy of the foetal lamb in utero. J Physiol. 1977;264(2):429-47.

22. Pasternak G. Opioids and their receptors: Are we there yet? Neuropharmacology. 2013.

23. MORLEY J S. CHEMISTRY OF OPIOID PEPTIDES. British Medical Bulletin. 1983;39(1):5-10.

24. Alavi FK, McCann JP, Sangiah S, Mauromoustakis A. Effects of naloxane on ad libitum intake and plasma insulin, glucose and free fatty acides in maintenance fed sheep. Dom Anim Endocr. 1991;8(109-115).

25. Westbrook SL, Chandler KD, McDowell GH. Immunization of pregnant ewes against somatotropin release inhibiting factor increases growth of twin lambs. Australian J Agri Res. 1993;44:229-238.

26. Csaba G. The present state in the phylogeny and ontogeny of hormone receptors. Horm Metab Res.1984;16(7):329-35.

27. Csaba G. Hormonal imprinting: phylogeny, ontogeny, diseases and possible role in present-day human evolution. Cell Biochem Funct. 2008;26(1):1-10.

28. Gow CB, Moore GP. Epidermal growth factor alters milk composition and fluid balance of lactating ewes. J Endocrinol. 1992;132(3):377-85.

29. Prosser CG, Fleet IR, Davis AJ, Heap RB. Mechanism of secretion of plasma insulin-like growth factor-I into milk of lactating goats. $J$ Endocrinol. 1991;131(3):459-66.

30. Koldovsky O. Search for role of milk-borne biologically active peptides for the suckling. J Nutr.1989;119(11):1543-51.

31. Koldovsky O, Illnerova H, Macho L, Strbak V, Stepankova R. Milkborne hormones: possible tools of communication between mother and suckling. Physiol Res. 1995;44(6):349-51.

32. Thomas MG, Amstalden M, Hallford DM, Silver GA, Garcia MD Keisler DH, et al. Dynamics of GHRH in third-ventricle cerebrospinal fluid of cattle: relationship with serum concentrations of $\mathrm{GH}$ and responses to appetite-regulating peptides. Domest Anim Endocrinol. 2009;37(4):196-205.

33. Kashio Y, Chihara K, Kaji H, Minamitani N, Kita T, Okimura Y, et al. Presence of growth hormone-releasing factor-like immunoreactivity in human cerebrospinal fluid. J Clinic Endocrinol Metab. 1985;60(2):396-8.

34. Purchas RW, Pearson AM, Hafs HD, Tucker HA. Some Endocrine Influences on the Growth and Carcass Quality of Holstein Heifers. J Anim Sci.1971;33(4):836-842.

35. Yambayamba E S, Price M A, Foxcroft G R. Hormonal status, metabolic changes, and resting metabolic rate in beef heifers undergoing compensatory growth. J Anim Sci.1996;74(1):57-69.

36. Fowden AL. Endocrine regulation of fetal growth. Reprod, Fertil Develop.1995;7(3):351-363.

37. Shahneh AZ. Manipulation of ovine adrenal function and animal productivity: Sydney; 1995 